The actinomycin $D$ was provided by Dr. E. Alpert of Merck, Sharp and Dohme Research Laboratories. William R. Pool

Florida State University, HARRY LIPNER

Department of Biological Science, Tallahasseo.

${ }_{1}$ Asdell, S. A., in The Ovary, edit. by Zuckerman, S. (Academic Press, 1962). Sawyer, C. S., in Gonadotropins (W. H. Freeman and Co., San Francisco, 1964).

Lipner, H. J., and Maxwell, B. A., Science, 131, 1737 (1960). Zachariae, F., and Jensen, C. D., Acta Endocrinol., 27, 343 (1958). Nalbandov, A. B., in Control of Ovulation, edit. by Villee, C. A. (Pergamon, New York, 1961).

${ }^{3}$ Espey, L. L., and Lipner, H. J., Amer. J. Physiol., 205, 1067 (1963). Espey, L. L., and Lipner, H. J., Fed. Proc., 23, 361 (1964)

${ }^{4}$ Reichert, L. E., Endocrinol., 71, 838 (1963).

Edelman, I., Bogoroch, R., and Porter, G., Proc. U.S. Nat. Acad. Sci., 50, 1169 (1963); Hamilton, T., ibid., 51, 83 (1964). Talway, G. P., and Segal, S.J., ibid.,50, 226 (1963). Ui, H., and Mueller, G., ibid., 256. Rasmussen, S.J., ibid., 50, 226 (1963). Ui, H., and Mueller, G., ibid., 256.

- Reich, E., Cancer Res., 23, 1428 (1963); Science, 143, 684 (1964).

\section{Modification of Visual Critical Flicker Fusion Frequency by Intermittent Auditory Stimuli}

KRAVKov ${ }^{1,2}$ found that visual critical flicker fusion frequency was modified by auditory stimuli, but other workers failed to confirm this ${ }^{3,4}$.

The experiments to be described here wore suggested by the demonstration of a modifying effect of intermittent light of varying frequency on critical flicker fusion frequency ${ }^{5,6}$. The relationship between critical flicker fusion frequency and the adapting frequency was almost linear between adapting frequencies of 24 and $54 \mathrm{c} / \mathrm{s}$. Because the exposure of one eye to the adapting light altered the critical flicker fusion frequency of the other, the phonomenon is probably central in origin.

Visual critical flicker fusion frequency was measured by 'Turner's technique ${ }^{6}$. It was defined as the fastest rate at which the neon light source was considered to be flickering as opposed to being steady. The threshold was determined either by an approach from a lower to a higher frequency (ascending threshold) or vice versa (descending threshold). Audible 'clicks' of varying frequency were derived from an oscillator constructed on the 'module' system? and were presented to the subject through a loud speaker.

The ascending $(A)$ and descending $(D)$ thresholds of critical flicker fusion frequency of six subjects were tested after exposure for 1 min to auditory 'clicks' at 25 or at $50 \mathrm{c} / \mathrm{s}$., or after a period of silence. The order in which the various frequencies of sound were given and ascending and descending thresholds were measured was randomized in a latin square arrangement. The results are given in Table 1.

Table 1. EXP. 1. EFFECT OF INTERMITTENT SOUND $A T 25$ AND $50 \mathrm{c} / \mathrm{s}$ ON ASCENDING $(A)$ AND DFSCENDING $(D)$ THREsholds OF CRITICAL Flicker FUSION FREQLENCY (c.f.f.f.

$n=6 \quad 5$ per cent critical difference $=0.74 \mathrm{c} / \mathrm{s}$

\begin{tabular}{llll} 
& & \multicolumn{2}{c}{ Mean c.f.f.f. $(\mathrm{c} / \mathrm{s})$} \\
& & $A$ & $D$ \\
No sonind & & $35 \cdot 5$ & $35 \cdot 0$ \\
Adapting sound & 25 & $36 \cdot 0$ & $35 \cdot 0$ \\
$\quad$ frequency $(\mathrm{c} / \mathrm{s})$ & 50 & $36 \cdot 25$ & $35 \cdot 75$
\end{tabular}

Table 2. FXP. 2. EFFECTS OF INTERMITTENT SOUND $(0-80 \mathrm{c} / \mathrm{s})$ ON ASCENDING $(A)$ AND DESCENDING $(D)$ THRESHOLDS OF c.f.f.f. $n=8 \quad 5$ per cent critical difference $=0.54 \mathrm{c} / \mathrm{s}$

$$
\begin{array}{lcccc} 
& \multicolumn{4}{c}{\text { Adapting sound frequency }(\mathrm{c} / \mathrm{s})} \\
& 0 \cdot 20 & 20 & 40 \\
\text { C.f.f.f. } A & 35 \cdot 25 & 35 \cdot 5 & 37 \cdot 0 & 36 \cdot 75 \\
\text { (c/s) } D & 35 \cdot 25 & 35 \cdot 75 & 35 \cdot 75 & 36 \cdot 5
\end{array}
$$

The mean ascending threshold of critical flicker fusion frequency after exposure to sound at $50 \mathrm{c} / \mathrm{s}$ was significantly higher than that without sound, while that after $25 \mathrm{c} / \mathrm{s}$ had an intermediate value. The mean descending threshold after $50 \mathrm{c} / \mathrm{s}$ was significantly higher than that after $25 \mathrm{c} / \mathrm{s}$ or that without sound, these latter two having identical values.
In a second experiment using the same method but in a sound-proof room, adapting frequencies of 20,40 and $80 \mathrm{c} / \mathrm{s}$ were used. Determinations were randomized to eliminate any order effect. Table 2 shows that visual critical flicker fusion frequency rose as the adapting auditory frequency increased. The ascending threshold rose sharply between 20 and $40 \mathrm{c} / \mathrm{s}$ while the descending threshold rose steeply betweon 40 and $80 \mathrm{c} / \mathrm{s}$.

These preliminary experiments suggest that there is an intersensory effect of intermittent sound of varying frequency on critical flicker fusion frequency.

We thank Mr. P. M. G. Bell for the design of the apparatus.

\section{Paul Turner*}
Department of Pharmacology,
St. Bartholomew's Hospital
Medical College, E.C.1.

JohN V. SMakT

Research and Development Division,

Smith Kline and French Lab., Ltd.,

Welwyn Garden City, Herts.

* Now at Medical Professorial Unit, St. Bartholomew's Hospital, E.C.1.

${ }^{1}$ Kravkov, S. V., Fiziol. Zhur., 19, 826 (1935).

${ }^{2}$ Kravkov, S. V., Acta med. U.R.S.S., 2, 461 (1939).

${ }^{3}$ Simonson, E., Fox, M. S., and Enzer, N., Arch. Otolaryngot., 38, 245 (1943).

${ }^{4}$ Knox, G. W., J. Gen. Psychol., 33, 121, 139 (1945).

${ }^{5}$ Ajpern, M., and Sugiyama, S., J. Opt. Soc. Amer., 51, 1379 (1961).

Turner, P., J. Physiol., 171, 6P (1964).

${ }^{7}$ Bell, P. M. G., J. Physiol., 161, 6P (1961).

\section{PHARMACOLOGY}

\section{Effect of Snake Venom and Endotoxin on Cortical Electrical Activity}

THE effects of a lethal injection of cobra venom, rattlesnake venom, or $E$. coli endotoxin on the cardiovascular system of the dog and monkey have been described previously in detail. The administration of endotoxin results in hypotension, acidosis, hæmolysis, and renal failure ${ }^{1-4}$. A similar effect is seen following the administration of snake venom ${ }^{5,6}$. No reports, however, describe the effects of these compounds on the central nervous system. The purpose of work recorded here, therefore, was to determine if a change in cortical electrical activity follows a lethal injection of these toxins.

Thirty adult mongrel dogs and fifteen monkeys of the Cynapthecoid group (sooty mangabey) were used. All animals were anæsthetized with pentobarbital sodium $(30 \mathrm{mg} / \mathrm{kg})$. Arterial blood pressure was continuously recorded using a Statham strain gauge and an $E$ and $M$ six-channel physiograph. The cortical electrical activity of the right and left hemispheres of the brain was monitored using bipolar silver electrodes placed directly on the dura of each hemisphere. Continuous electroencephalograms were recorded prior to and for up to $10 \mathrm{~h}$ after the intravenous administration of the toxin. The animals were divided at random into the following three groups:

Group I: 10 dogs and 5 monkeys receiving $0.5 \mathrm{mg} / \mathrm{kg}$ crude cobra venom (Naja naja); Group II : 10 dogs and 5 monkeys receiving $0.5 \mathrm{mg} / \mathrm{kg}$ crude rattlesnake venom (Crotalus admanteus); Group III: 10 dogs and 5 monkeys receiving $1.0 \mathrm{mg} / \mathrm{g}$ endotoxin ( $E$. coli) (Difco).

Table 1 presents a composite of the results obtained from the three groups of animals used in this work. The effect of each toxin on cortical electrical activity is indicated. The change observed in EEG is of an all-or-none nature, being characterized by either a complete loss of activity, or no alteration at all. All animals in Groups I and II showed complete or almost complete EEG silence within 1 min after having received either venom. In contrast, none of the dogs or monkeys in Group III, which received endotoxin, showed any alteration in 